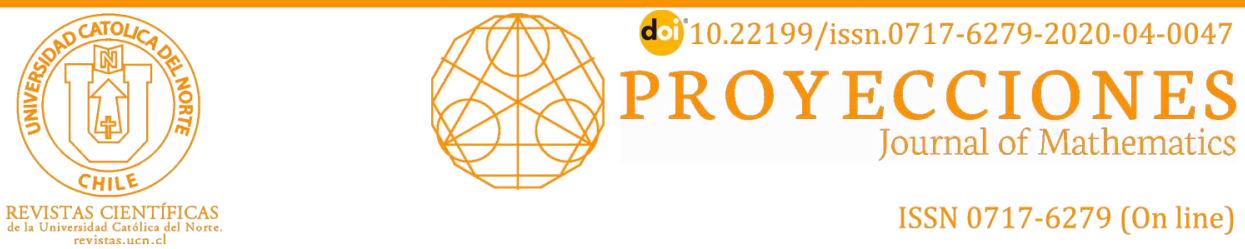

\title{
M-Polynomial and topological indices of benzene ring embedded in p-type surface network
}

\author{
Murat Cancan ${ }^{1}$ (1) orcid.org/0000-0002-8606-2274 \\ Süleyman Ediz ${ }^{2}$ (D) orcid.org/0000-0003-0625-3634:

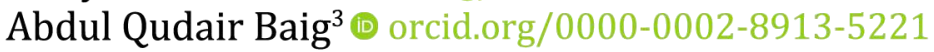 \\ Waqas Khalid ${ }^{4}$ (1) orcid.org/0000-0001-5527-6563 \\ ${ }^{1}$ Van Yznc Yil University, Faculty of Education, Van, Turkey. \\ घm_cencen@yahoo.com \\ ${ }^{2}$ Van Yznc Yil University, Faculty of Education, Van, Turkey. \\ suleymanediz@yyu.edu.tr \\ ${ }^{3}$ COMSATS Institute of Information Technology, Dept. of Mathematics, Attock, Pakistan. \\ aqbaig1@gmail.com \\ ${ }^{4}$ Punjab College of Commerce and Science, Attock, Pakistan \\ waqas.khalid38@gmail.com \\ Received: February 2020 | Accepted: May 2020
}

\begin{abstract}
:
The representation of chemical compounds and chemical networks with the M-polynomials is a new idea and it gives nice and good results of the topological indices. These results are used to correlate the chemical compounds and chemical networks with their chemical properties and bioactivities.

Particular attention is paid to the derivation of the $M$ polynomia- for the benzene ring embedded in the P-type surface network in $2 D$. Furthermore, the topological indices based on the degrees are also derived by using the general form of M-polynomial of benzene ring embedded in the P-type surface network $B R(m, n)$. In the end, the graphical representation and comparison of the M-polynomial and the topological indices of benzene ring embedded in P-type surface network in $2 D$ are described.
\end{abstract}

Keywords: M-polynomial; Topological indices; Surface network

$\operatorname{MSC}(2020): 05 C 09$.

\section{Cite this article as (IEEE citation style):}

M. Cancan, S. Ediz, A. Q. Baig, and W. Khalid, "M-Polynomial and topological indices of benzene ring embedded in p-type surface network", Proyecciones (Antofagasta, On line), vol. 39, no. 4, pp. 749-768, Aug. 2020, doi: 10.22199/issn.0717-6279-2020-040047.

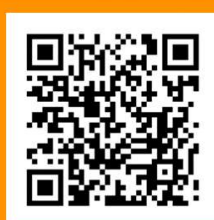

Article copyright: (C) 2020 Murat Cancan, Süleyman Ediz, Abdul Qudair Baig, and Waqas Khalid. This is an open access article distributed under the terms of the Creative Commons License, which permits unrestricted use and distribution provided the original author and source are credited. 


\section{Introduction}

The chemical compounds can be represented by using the mathematical tools of graph theory. The mathematical models that are based on the polynomials of the chemical compounds and crystal structures can be used in order to predict and forecast their chemical properties and bioactivities. Mathematical chemistry is a rich in tools like functions and polynomials which predict the properties of molecular graphs and crystal structures. The topological descriptors are the numerical parameters of the chemical graph which characterize its topology and are usually graph invariants. They explain the structure of chemical compound mathematically and are utilized in the study of quantitative structure properties and activities relationships (QSPR/QSAR).

A topological index is a numerical value which describes and explains an important information about the chemical structure. A great variety of such indices are studied and used in theoretical chemistry, pharmaceutical researchers, in drugs and in different areas of science. The properties like boiling point, strain energy, viscosity, fracture toughness and heat of formation, etc are connected to the chemical structure under study. This fact plays a major role in the field of chemical graph theory $[4,5,8,16,17,19,20,21,24,27,37,38,41,42]$.

The computation of general polynomial is formed whose derivatives or integrals or composition of both, are evaluated at some particular point. Then, the simplified form yields molecular descriptor. For instance, there are polynomials like forgotten polynomials, Zagreb polynomials, Hosoya polynomials but these polynomials gives rise to one or two topological indices $[7,13,23,26]$. Hosoya polynomial is a polynomial whose derivatives are evaluated at 1 gives Wiener and hyper Wiener index [15]. The Hosoya polynomial and Zagreb polynomials are considered to be the general form of in the determination of distance based and degree based indices respectively. The M-polynomial is a new and recent polynomial. It will open up new results of chemical graphs and insights in the study of topological descriptors based on degrees. The main importance of this polynomial is that it can give exact forms of more than ten degree based molecular descriptors $[9,33]$. The rapid development and advancements are being made in this 
new polynomial. Recently, Young Chel Kwun computed M-polynomial and topological indices of $\mathrm{V}$-phenylenic nanotube and nanotori [30].

The M-polynomial of a graph $G$ is formulated as [9]:

$$
M(G ; x, y)=\sum_{\delta \leq i \leq j \leq j} m_{i j}(G) x^{i} y^{j}
$$

where $m_{i j}(G)$ is the number of edges $u v \in E(G)$ such that $\left(d_{u}, d_{v}\right)=(i, j)$, $\delta=\min d_{v} \mid v \in V(G)$ and $\Delta=\max d_{v} \mid v \in V(G)$.

The path number was the first distance based topological index defined by Wiener [43] in 1947. This index is now called as Wiener index. It has many famous mathematical and chemical applications [12,43]. Later on, Milan Randić proposed and formulated the Randić index of a graph $G$ $R_{-\frac{1}{2}}(G)$.

$$
R_{-\frac{1}{2}}(G)=\sum_{u v \in E(G)} \frac{1}{\sqrt{d_{u} d_{v}}} .
$$

The general Randić index was proposed and defined independently by Bollobás et al. [3] and Amic et al. [1]. Due to its useful and important results in the field of mathematical chemistry, it has been widely used by both mathematicians and chemists. For a survey of these results, see the references $[6,28,31,36]$. The general Randić index and inverse Randić index are formulated as:

$$
R_{\alpha}(G)=\sum_{u v \in E(G)}\left(d_{u} d_{v}\right)^{\alpha}, \quad R R_{\alpha}(G)=\sum_{u v \in E(G)} \frac{1}{\left(d_{u} d_{v}\right)^{\alpha}} .
$$

The first and second Zagreb index is introduced by Gutman an Trinajstić $[23,25,40]$. Both first and second Zagreb index and the second modified index are formulated as:

$$
\begin{gathered}
M_{1}(G)=\sum_{u v \in E(G)}\left(d_{u}+d_{v}\right), \\
M_{2}(G)=\sum_{u v \in E(G)}\left(d_{u} d_{v}\right),
\end{gathered}
$$




$$
{ }^{m} M_{2}(G)=\sum_{u v \in E(G)} \frac{1}{d_{u} d_{v}} .
$$

Recently, the Symmetric division deg index of a graph $G$ is introduced [22]. It is significant index which is used to determine the total surface area of poly-chloro-bi-phenyls [32] and is defined as:

$$
S D D(G)=\sum_{u v \in E(G)}\left(\frac{\min \left(d_{u}, d_{v}\right)}{\max \left(d_{u}, d_{v}\right)}+\frac{\max \left(d_{u}, d_{v}\right)}{\min \left(d_{u}, d_{v}\right)}\right) .
$$

The other version of Randic index is harmonic index [44] and is defined as:

$$
H(G)=\sum_{u v \in E(G)} \frac{2}{d_{u}+d_{v}} .
$$

The inverse sum index is formulated as [35]:

$$
I(G)=\sum_{u v \in E(G)} \frac{d_{u} d_{v}}{d_{u}+d_{v}} .
$$

The augmented Zagreb index gives best approximation of heat of formation of alkanes $[14,18]$. It is formulated as [29]:

$$
A(G)=\sum_{u v \in E(G)}\left(\frac{d_{u} d_{v}}{d_{u}+d_{v}-2}\right)^{3}
$$

Let $M(G ; x, y)=f(x, y)$ then the following Table 1.1 relates above described topological indices with M-polynomial [9].

Where

$$
\begin{gathered}
Q_{\alpha}(f(x, y))=x^{\alpha} f(x, y), \quad J(f(x, y))=f(x, x) \\
S_{x}=\int_{0}^{x} \frac{f(t, y)}{t} d t, \quad S_{y}=\int_{0}^{y} \frac{f(x, t)}{t} d t \\
D_{x}=x \frac{\partial(f(x, y))}{\partial x}, \quad D_{y}=y \frac{\partial(f(x, y))}{\partial y}
\end{gathered}
$$




\begin{tabular}{|c|c|}
\hline Topological Descriptor & Derivation from $f(x, y)$ \\
\hline$R_{\alpha}(G), \alpha \in R$ & $\left.\left(D_{x}^{\alpha} D_{y}^{\alpha}\right)(f(x, y))\right|_{x=y=1}$ \\
\hline$R R_{\alpha}(G), \alpha \in R$ & $\left.\left(S_{x}^{\alpha} S_{y}^{\alpha}\right)(f(x, y))\right|_{x=y=1}$ \\
\hline$M_{1}(G)$ & $\left.\left(D_{x}+D_{y}\right)(f(x, y))\right|_{x=y=1}$ \\
\hline$M_{2}(G)$ & $\left.\left(D_{x} D_{y}\right)(f(x, y))\right|_{x=y=1}$ \\
\hline$M_{2}(G)$ & $\left.\left(S_{x} S_{y}\right)(f(x, y))\right|_{x=y=1}$ \\
\hline$H(G)$ & $\left.2 S_{x} J(f(x, y))\right|_{x=1}$ \\
\hline$S D D(G)$ & $\left.\left(D_{x} S_{y}+S_{x} D_{y}\right)(f(x, y))\right|_{x=y=1}$ \\
\hline$I(G)$ & $\left.S_{x} J D_{x} D_{y}(f(x, y))\right|_{x=1}$ \\
\hline$A(G)$ & $\left.S_{x}^{3} Q_{-2} J D_{x}^{3} D_{y}^{3}(f(x, y))\right|_{x=1}$ \\
\hline
\end{tabular}

Table 1.1: The relationship of topological indices with M-polynomial.

\section{Main Results and Discussion}

O'Keeffe et al. have distributed around a quarter century a letter managing two 3D systems of benzene, one of the structure was known as $6.82 \mathrm{P}$ (or ad-ditionally polybenzene) and has a place with the space gather $\operatorname{Im} 3 \mathrm{~m}$, comparing to the P-type surface [34]. Actually, this is inserting of the hexagon fix in the surface of negative ebb and flow P. The P-type surface is coordinated to the cartesian arranges in the Euclidean space. More about this intermittent surface the reader can discover in $[10,11]$. This structure was required to be combined as 3D carbon solids: be that as it may, in our best learning, no such a combination was accounted for as such. This goal was to awaken the enthusiasm of researchers to the atomic acknowledgment of such pleasant thoughts in carbon nanoscience, as much as the graphenes were picked up a moment Nobel prize after $C_{60}$, also the immediate union of fullerenes is currently a reality, see detail in $[2,39]$. 


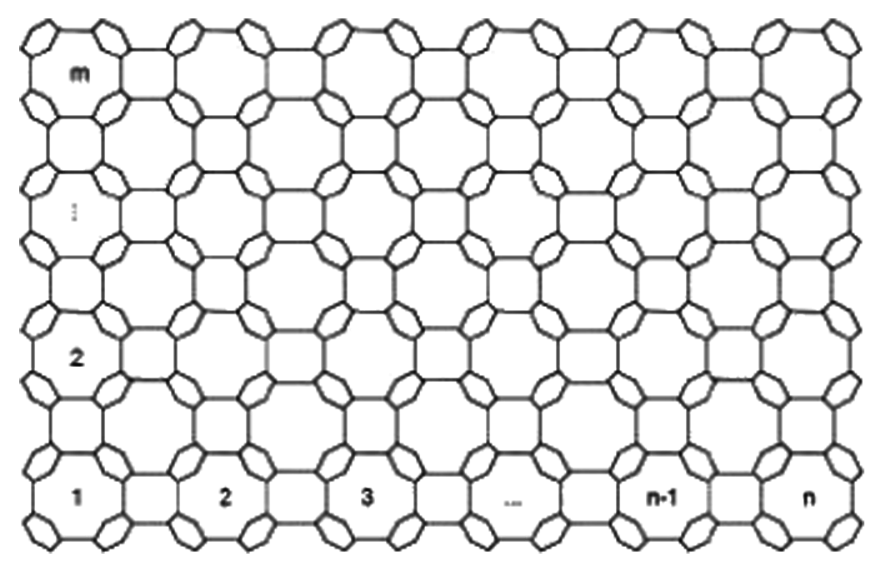

Figure 2.1: Chemical graph of benzene ring embedded in P-type surface network in $2 \mathrm{D}$.

The molecular graph of benzene ring embedded in the P-type surface network is depicted in fig. 2. The cardinality of vertices and edges of the given molecular graph are $24 m n$ and $32 m-2 m-2 n$ respectively. The vertex set consists of two vertex partitions in the benzene ring embedded in the P-type surface network. The table 2.1. Furthermore, the edge set consists of three edge partitions. The first edge partition contains $4 m+4 n$ edges $u v$, where $\operatorname{deg}(u)=\operatorname{deg}(v)=2$. The second edge partition contains $16 m n$ edges $u v$, where $\operatorname{deg}(u)=2$ and $\operatorname{deg}(v)=3$. The third edge partition contains $16 m n-2 m-2 n$ edges $u v$, where $\operatorname{deg}(u)=\operatorname{deg}(v)=3$. The table 2.2 shows the edges partition in the benzene ring embedded in the P-type surface network. We compute the M-polynomial of the benzene ring embedded in the P-type surface network. Also, we present the graphically representation of this graph in 2D and 3D by using Maple 13. In the end, we compute and simplify the topological indices by using the M-polynomial of benzene ring embedded in the P-type surface network. 


\begin{tabular}{|c|c|c|}
\hline$d_{v}$ & 2 & 3 \\
\hline Frequency & $8 m n+4 m+4 n$ & $16 m n-4 m-4 n$ \\
\hline
\end{tabular}

Table 2.1: Vertex partition of benzene ring embedded in the P-type surface network based on degrees of each vertex.

\begin{tabular}{|c|c|c|c|}
\hline$\left(d_{u}, d_{v}\right)$ & $(2,2)$ & $(2,3)$ & $(3,3)$ \\
\hline Frequency & $4 m+4 n$ & $16 m n$ & $16 m n-6 m-6 n$ \\
\hline
\end{tabular}

Table 2.2: Edge partition of benzene ring embedded in the P-type surface network based on degrees of end vertices of each edge.

\section{M-Polynomial of Benzene Ring Embedded in P-Type Net- work}

Consider the graph of a benzene ring embedded in the P-type surface network $B R(m, n)$ with $m, n>1$, then the M-polynomial of this graph is given by,

$M(B R(m, n) ; x, y)=(4 m+4 n) x^{2} y^{2}+(16 m n) x^{2} y^{3}+(16 m n-6 m-6 n) x^{3} y^{3}$

Proof. Let the graph of a benzene ring embedded in the P-type surface network with $m$ and $n$ are the number of unit cells in the columns and rows respectively. It consists of two vertex and three edge partitions.

From the fig.1, it is easy to observe that

$$
\begin{gathered}
|V(B R(m, n))|=24 m n \\
|E(B R(m, n))|=32 m n-2 m-2 n
\end{gathered}
$$

From table 2.1, it can be seen that there are two partitions of the vertex set of benzene ring embedded in the P-type surface network. 


$$
\begin{aligned}
& V_{1}(B R(m, n))=\left\{u \in V(B R(m, n)) \mid d_{u}=2\right\}, \\
& V_{2}(B R(m, n))=\left\{u \in V(B R(m, n)) \mid d_{u}=3\right\}
\end{aligned}
$$

such that

$$
\left|V_{1}(B R(m, n))\right|=8 m n+4 m+4 n,\left|V_{2}(B R(m, n))\right|=16 m n-4 m-4 n
$$

From table 2.2, it can be seen that there are three partitions of the edge set of benzene ring embedded in the P-type surface network.

$$
\begin{aligned}
& E_{1}(B R(m, n))=\left\{u v \in E(G) \mid d_{u}=2, \quad d_{v}=2\right\}, \\
& E_{2}(B R(m, n))=\left\{u v \in E(G) \mid d_{u}=2, \quad d_{v}=3\right\}, \\
& E_{3}(B R(m, n))=\left\{u v \in E(G) \mid d_{u}=3, \quad d_{v}=3\right\},
\end{aligned}
$$

such that

$$
\begin{aligned}
& \left|E_{1}(B R(m, n))\right|=4 m+4 n, \quad\left|E_{2}(B R(m, n))\right|=16 m n \\
& \left|E_{3}(B R(m, n))\right|=16 m n-6 m-6 n
\end{aligned}
$$

Now, applying the definition of M-polynomial to the graph of benzene ring P-type network, we have

$$
\begin{gathered}
M(B R(m, n) ; x, y)=\sum_{i \leq j} m_{i j} x^{i} y^{j} \\
=\sum_{i \leq j} m_{i j} x^{i} y^{j}=\sum_{2 \leq 2} m_{22} x^{2} y^{2}+\sum_{2 \leq 3} m_{23} x^{2} y^{3}+\sum_{3 \leq 3} m_{33} x^{3} y^{3} \\
=\sum_{u v \in E_{1}(G)} m_{22} x^{2} y^{2}+\sum_{u v \in E_{2}(G)} m_{23} x^{2} y^{3}+\sum_{u v \in E_{3}(G)} m_{33} x^{3} y^{3} \\
=\left|E_{1}(G)\right| x^{2} y^{2}+\left|E_{2}(G)\right| x^{2} y^{3}+\left|E_{3}(G)\right| x^{3} y^{3}
\end{gathered}
$$


$M(B R(m, n) ; x, y)=(4 m+4 n) x^{2} y^{2}+(16 m n) x^{2} y^{3}+(16 m n-6 m-6 n) x^{3} y^{3}$.

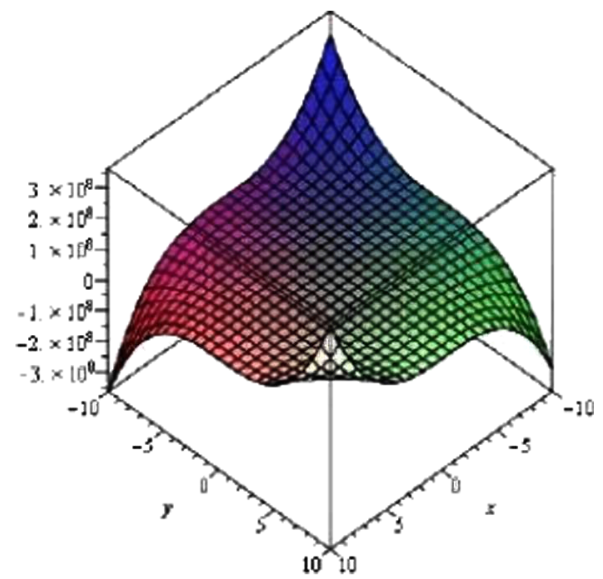

Figure 3.1: The 3D plot of M-polynomial of benzene ring P-type surface network.

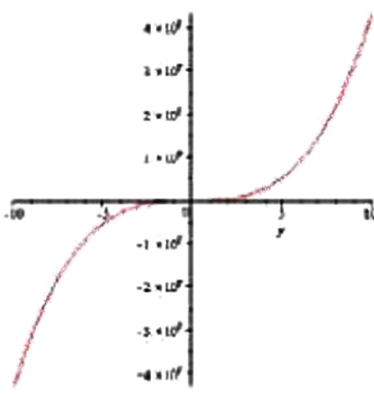

(a)

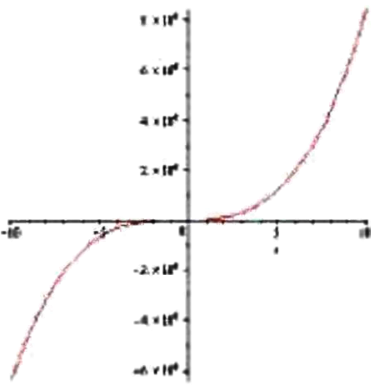

(b)

Figure 3.2: (a) The 2D plot of M-polynomial of benzene ring P-type surface network by fixing the parameter $x$. (b) The 2D plot of M-polynomial of benzene ring P-type surface network by fixing the parameter $y$.

The 3D graphical representation of M-polynomial of benzene ring embedded in the P-type surface network $B R(m, n)$ is depicted in fig. 3.1. This is plotted by using Maple 13. The graph shows different behavior by fixing the values of $m$ and $n$ and changing the parameters $x$ and $y$. The 2D 
graphical representation of M-polynomial of $B R(m, n)$ can be formed by considering the parameter $x$ to be the positive value, then the graph increases by increasing the values of $x$ and the graph lies in the first and third quadrant. The same behavior occurs for positive values of $y$, as depicted in fig. 3.2(a) and 3.2(b). If the parameter $x$ is taken to be negative value, then the graph increases by increasing the values of $x$ and the graph lies in the second and fourth quadrant. The same behavior occurs for negative values of $y$.

\section{Topological Indices Derived From M-Polynomial of $B R(m, n)$}

The following proposition computes the degree based topological indices that are derived from the M-polynomial of the molecular graph of benzene ring P-type surface network.

Consider the graph $G$ be a benzene ring embedded in the P-type surface network with $m, n>1$, then we have the following degree based topological indices,

1. $M_{1}(G)=176 m n-20 m-20 n$

2. $M_{2}(G)=240 m n-38 m-38 n$

3. ${ }^{m} M_{2}(G)=\frac{40 m n+3 m+3 n}{9}$

4. $S D D(G)=\frac{200 m n-12 m-12 n}{3}$

5. $H(G)=\frac{176 m n}{15}$

6. $I(G)=\frac{24 m n-25 m-25 n}{5}$

7. $A(G)=\frac{9928 m n-1163 m-1163 n}{32}$

8. $R R_{\alpha}(G)=(16 m n)\left(\frac{2^{\alpha}+3^{\alpha}}{2^{\alpha} 3^{2 \alpha}}\right)+(m+n)\left(\frac{4\left(3^{2 \alpha}\right)-6\left(2^{2 \alpha}\right)}{6^{2 \alpha}}\right)$

9. $R_{\alpha}(G)=(16 m n)\left(3^{2 \alpha}+6^{\alpha}\right)+(m+n)\left(4\left(2^{2 \alpha}\right)-6\left(3^{2 \alpha}\right)\right)$

Proof. Consider the molecular graph of $G$ be a benzene ring embedded in the P-type surface network with $m, n>1$, its M-polynomial is simplified in the first theorem. Now, consider the 


$$
\begin{gathered}
M(G ; x, y)=f(x, y) \\
f(x, y)=(4 m+4 n) x^{2} y^{2}+(16 m n) x^{2} y^{3}+(16 m n-6 m-6 n) x^{3} y^{3}
\end{gathered}
$$

In order to prove the above nine results, we use the following formulas.

$$
\begin{gathered}
Q_{\alpha}(f(x, y))=x^{\alpha} f(x, y), \quad J(f(x, y))=f(x, x), \\
S_{x}=\int_{0}^{x} \frac{f(t, y)}{t} d t, \quad S_{y}=\int_{0}^{y} \frac{f(x, t)}{t} d t \\
D_{x}=x \frac{\partial(f(x, y))}{\partial x}, \quad D_{y}=y \frac{\partial(f(x, y))}{\partial y}
\end{gathered}
$$

Now, we have the following computations

$$
D_{x}(f(x, y))=2(4 m+4 n) x^{2} y^{2}+2(16 m n) x^{2} y^{3}+3(16 m n-6 m-6 n) x^{3} y^{3}
$$

$$
D_{y}(f(x, y))=2(4 m+4 n) x^{2} y^{2}+3(16 m n) x^{2} y^{3}+3(16 m n-6 m-6 n) x^{3} y^{3}
$$

(4.3) $D_{x} D_{y}(f(x, y))=4(4 m+4 n) x^{2} y^{2}+6(16 m n) x^{2} y^{3}+9(16 m n-6 m-6 n) x^{3} y^{3}$

$$
S_{x}(f(x, y))=\frac{(4 m+4 n)}{2} x^{2} y^{2}+\frac{(16 m n)}{2} x^{2} y^{3}+\frac{(16 m n-6 m-6 n)}{3} x^{3} y^{3}
$$

$$
S_{x} S_{y}(f(x, y))=\frac{(4 m+4 n)}{4} x^{2} y^{2}+\frac{(16 m n)}{6} x^{2} y^{3}+\frac{(16 m n-6 m-6 n)}{9} x^{3} y^{3}
$$

$$
S_{x} D_{y}(f(x, y))=(4 m+4 n) x^{2} y^{2}+\frac{3(16 m n)}{2} x^{2} y^{3}+(16 m n-6 m-6 n) x^{3} y^{3}
$$

$$
D_{x} S_{y}(f(x, y))=(4 m+4 n) x^{2} y^{2}+\frac{2(16 m n)}{3} x^{2} y^{3}+(16 m n-6 m-6 n) x^{3} y^{3}
$$


$D_{x}^{\alpha} D_{y}^{\alpha}(f(x, y))=2^{2 \alpha}(4 m+4 n) x^{2} y^{2}+6^{\alpha}(16 m n) x^{2} y^{3}+3^{2 \alpha}(16 m n-6 m-6 n) x^{3} y^{3}$ (4.8)

$S_{x}^{\alpha} S_{y}^{\alpha}(f(x, y))=\frac{(4 m+4 n)}{2^{2 \alpha}} x^{2} y^{2}+\frac{(16 m n)}{6^{\alpha}} x^{2} y^{3}+\frac{(16 m n-6 m-6 n)}{3^{2 \alpha}} x^{3} y^{3}$

$$
S_{x} J(f(x, y))=\frac{(4 m+4 n)}{4} x^{4}+\frac{(16 m n)}{5} x^{5}+\frac{(16 m n-6 m-6 n)}{6} x^{6}
$$

(4.11) $S_{x} J D_{x} D_{y}(f(x, y))=(4 m+4 n) x^{4}+\frac{6(16 m n)}{5} x^{5}+\frac{3(16 m n-6 m-6 n)}{2} x^{6}$

$S_{x}^{3} Q_{-2} J D_{x}^{3} D_{y}^{3}(f(x, y))=8(4 m+4 n) x^{2}+8(16 m n) x^{3}+\frac{729(16 m n-6 m-6 n)}{64} x^{4}$

Now by using the above all values from equation 4.1 to 4.12 in table 1.1 to get the topological indices defined in the table 1.1 are obtained.

1. $M_{1}(G)=176 m n-20 m-20 n$

2. $M_{2}(G)=240 m n-38 m-38 n$

3. ${ }^{m} M_{2}(G)=\frac{40 m n+3 m+3 n}{9}$

4. $S D D(G)=\frac{200 m n-12 m-12 n}{3}$

5. $H(G)=\frac{176 m n}{15}$

6. $I(G)=\frac{24 m n-25 m-25 n}{5}$

7. $A(G)=\frac{9928 m n-1163 m-1163 n}{32}$

8. $R R_{\alpha}(G)=(16 m n)\left(\frac{2^{\alpha}+3^{\alpha}}{2^{\alpha} 3^{2 \alpha}}\right)+(m+n)\left(\frac{4\left(3^{2 \alpha}\right)-6\left(2^{2 \alpha}\right)}{6^{2 \alpha}}\right)$

9. $R_{\alpha}(G)=(16 m n)\left(3^{2 \alpha}+6^{\alpha}\right)+(m+n)\left(4\left(2^{2 \alpha}\right)-6\left(3^{2 \alpha}\right)\right)$ 


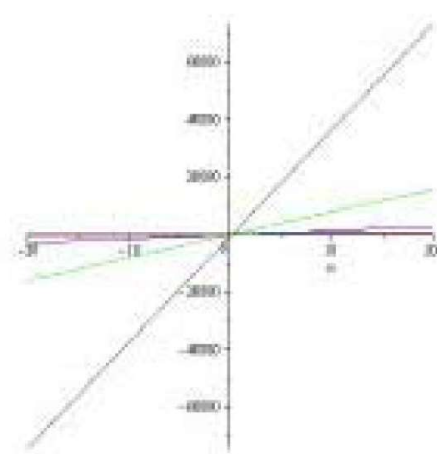

(ai)

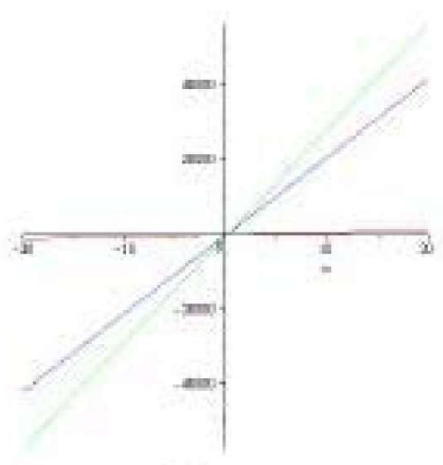

(b)

Figure 4.1: (a) Plot of symmetric division, harmonic, inverse sum and augmented Zagreb index for fix $n$ parameter. (b) Plot of first Zagreb, second Zagreb and modified Zagreb index for fix $m$ parameter.

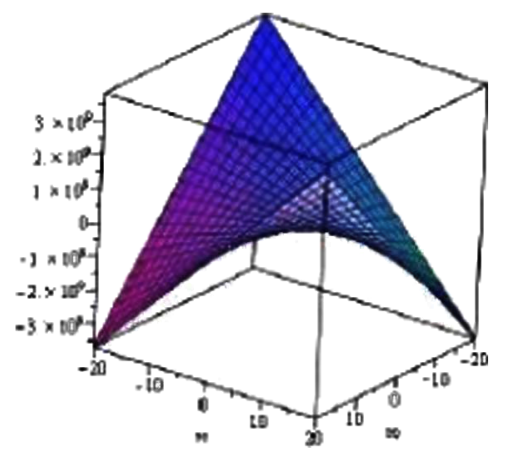

Figure 4.2: The 3D plot of Randić index for $B R(m, n)$.

The symmetric division, harmonic, inverse sum and augmented Zagreb indices are plotted by using Maple 13. The graphical representation depicts different behavior of indices by changing the parameters $m$ and $n$. The blue, green, red and black shows the symmetric division, harmonic, inverse sum and augmented Zagreb indices respectively, as depicted in fig. 4.1(a). The fig. 4.1(b) illustrates the first Zagreb index in blue color, second Zagreb index in green color and modified Zagreb index in red color. 
The 3d plot of Randić index and inverse Randić index are illustrated in the fig. 4.2 and fig. 4.3 respectively. It is clearly seen from the graphs that by increasing the values of the parameters $m$ and $n$, the graph of 4.2 increases faster as compared to the graph 4.3. It can be concluded that the Randić index increases faster then the inverse Randić index.

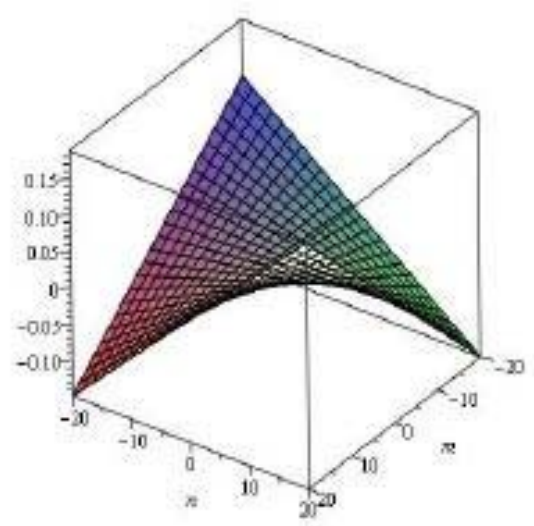

Figure 4.3: The 3D plot of inverse Randić index for $B R(m, n)$.

The 2D plot of inverse Randić index is depicted in fig. 4.4(a). This is achieved by using Maple 13 and fixing the value of the parameter $m$ or $n$. In both cases, if values of parameter increases then graph increases gradually and shows different behavior. The $2 \mathrm{D}$ plot of Randić index is depicted in fig. 4.4(b). By increasing the values of the parameters, the graph increases and depicts different behavior. 


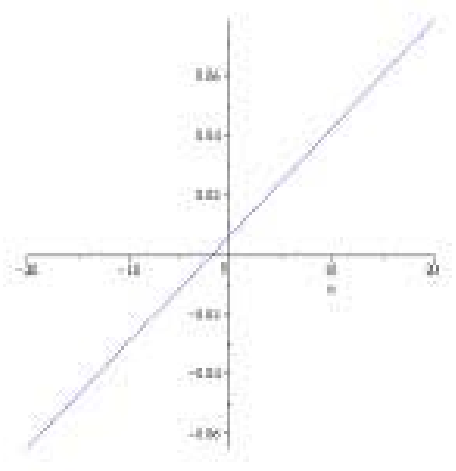

(a)

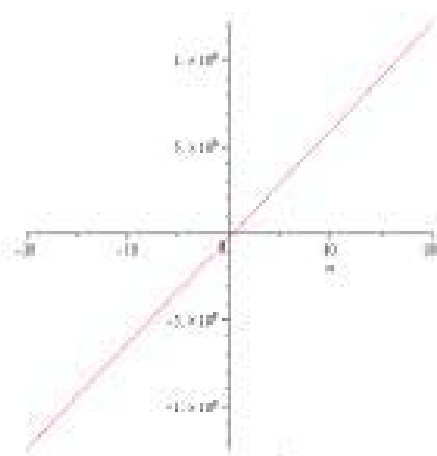

(b)

Figure 4.4: (a) The 2D plot of Randić for $B R(m, n)$. inverse Randić index for $B R(m, n)$.

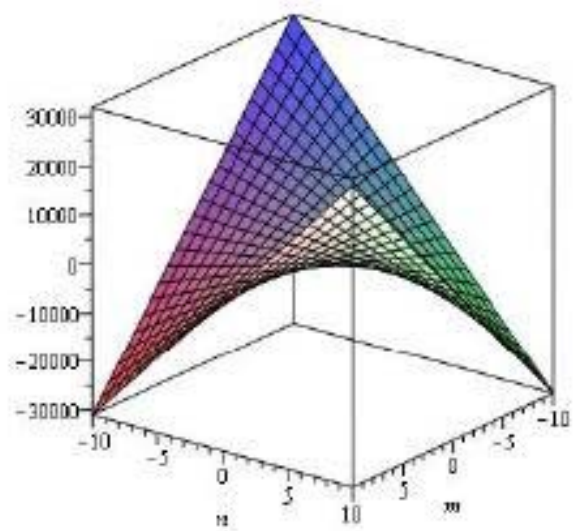

The fig. 4.5 illustrates the 3D plot of augmented Zagreb index for the molecular graph $B R(m, n)$. By increasing the values of the given parameters, the value of indices increases. The value indices of $B R(m, n)$ increases by changing the values of parameters $m$ and $n$. The indices derived here are the functions that depends on the values of parameters, where $m$ and $n$ are the independent parameters and the index is dependent parameter.

Figure 4.5: The 3D plot of augmented Zagreb index for $B R(m, n)$. 


\section{Conclusion}

We have computed the general form of M-polynomial for the molecular graph of benzene ring embedded in the P-type surface network $B R(m, n)$ for the first time. The graphical representation of M-polynomial of $B R(m, n)$ and some of its indices have plotted for different values of the given parameters. Furthermore, we have derived and simplified the exact results for degree based topological indices of $B R(m, n)$ from the M-polynomial of $B R(m, n)$.

In future, we will sketch and design some new chemical graphs/networks and compute their M-polynomial and examine their underlying topological properties.

\section{References}

[1] D. Amić, D. Bešlo, B. Lučić, S. Nikolić, and N. Trinajstić, "The vertex-connectivity index revisited", Journal of chemical information and computer sciences, vol. 38, no. 5, pp. 819-822, Aug. 1998, doi: 10.1021/ci980039b

[2] K. Yu. Amsharov and M. Jansen, A C78 fullerene precursor: toward the direct synthesis of higher fullerenes, The journal of organic chemistry, vol. 73, no. 7, pp. 2931-2934, Mar. 2008, doi: 10.1021/jo7027008

[3] B. Bollobás, P. Erdös, "Graphs of extremal weights", Ars combinatoria, vol. 50, pp. 225-233, 1998.

[4] A. Q. Baig, M. Imran, and H. Ali, "On topological indices of poly oxide, poly silicate, DOX, and DSL networks", Canadian journal of chemistry, vol. 93, no. 7, pp. 730-739, Mar. 2015, doi: 10.1139/cjc-2014-0490

[5] A. Q. Baig, M. Imran, W. Khalid, and M. Naeem, "Molecular description of carbon graphite and crystal cubic carbon structures", Canadian journal of chemistry, vol. 95, no. 6, pp. 674-686, Mar. 2017, doi: 10.1139/cjc2017-0083

[6] G. Caporossi, I. Gutman, P. Hansen, and L. Pavlović, "Graphs with maximum connectivity index", Computational biology and chemistry, vol. 27, no. 1, pp. 85-90, Feb. 2003, doi: 10.1016/S0097-8485(02)00016-5 
[7] K. C. Das, I. Gutman, "Some properties of the second Zagreb Index", MATCH communications in mathematical and in computer chemistry, vol. 52, pp. 103-112, 2004. [On line]. Available: https://bit.ly/2UG9Cmy

[8] H. Deng, J. Yang, and F. Xia, "A general modeling of some vertex-degree based topological indices in benzenoid systems and phenylenes", Computers \& mathematics with applications, vol. 61, no. 10, pp. 3017-3023, May 2011, doi: 10.1016/j.camwa.2011.03.089

[9] E. Deutsch and S. Klavzar, "M-Polynomial, and degree-based topological indices", Iranian journal of mathematical chemistry, vol. 6, no. 2, pp. 93-102, 2015, doi: 10.22052/IJMC.2015.10106

[10] M. V. Diudea, Ed., Nanostructures: novel architecture. New York, NY: Nova Science Publ., 2005.

[11] M. V. Diudea and C. L. Nagy, Periodic nanostructures. Dordrecht: Springer, 2007, doi: 10.1007/978-1-4020-6020-5

[12] A. A. Dobrynin, R. Entringer, and I. Gutman, "Wiener index of trees: theory and applications", Acta applicandae mathematicae, vol. 66, no. 3, pp. 211-249, May 2001, doi: 10.1023/A:1010767517079

[13] M. Eliasi and B. Taeri, "Hosoya polynomial of zigzag polyhex nanotorus", Journal of the Serbian Chemical Society, vol. 73, no. 3, pp. 311-319, 2008, doi: 10.2298/JSC0803311E

[14] E. Estrada, L. Torres, L. Rodríguez, and I. Gutman, "An atom-bond connectivity index: Modelling the enthalpy of formation of alkanes", Indian journal of chemistry, vol. 37A, pp. 849-855, 1998. [On line]. Available: https://bit.ly/2MXvsxH

[15] M. R. Farahani, "Computing fourth atom bond connectivity index of Vphenylenic nanotubes and nanotori", Acta chimica slovenica, vol. 60, no. 2, pp. 429-432, 2013. [On line]. Available: https://bit.ly/2C63opV

[16] M. R. Farahani, "Hosoya polynomial, Wiener and Hyper Wiener indices of some regular graphs", Informatics engineering, an international journal, vol. 1, no. 1, pp. 9-13, 2013. [On line]. Available: https://bit.ly/3d2OHR4

[17] M. R. Farahani, W. Gao, A. Q. Baig, and W. Khalid, "Molecular description of copper(II) oxide", Macedonian journal of chemistry and chemical engi- 
gineering, vol. 36, no. 1, pp. 93-99, Jun. 2017, doi: $10.20450 / \mathrm{mjcce} .2017 .1138$

[18] B. Furtula, A. Graovac, and D. Vukičević, "Augmented Zagreb index", Journal of mathematical chemistry, vol. 48, no. 2, pp. 370-380, Aug. 2010, doi: $10.1007 / \mathrm{s} 10910-010-9677-3$

[19] W. Gao and M. R. Farahani, "Degree-based indices computation for special chemical molecular structures using edge dividing method", Applied mathematics and nonlinear sciences, vol. 1, no. 1, pp. 99-122, Jan. 2016, doi: 10.21042/AMNS.2016.1.00009

[20] W. Gao, M. R. Farahani, and L. Shi, "Forgotten topological index of some drug structures", Acta medica mediterranea, vol. 32, pp. 579-585, 2016. [On line]. Available: https://bit.ly/2UJ8nDc

[21] W. Gao, M. K. Siddiqui, M. Imran, M. K. Jamil, and M. R. Farahani, "Forgotten topological index of chemical structure in drugs", Saudi pharmaceutical journal, vol. 24, no. 3, pp. 258-264, May 2016, doi: 10.1016/j.jsps.2016.04.012

[22] C. K. Gupta, V. Lokesha, B. S. Shetty, and P. S. Ranjini, "On the symmetric division deg index of graph", Southeast Asian bulletin of mathematics, vol. 41, no. 1, pp. 1-23, 2016. [On line]. Available: https://bit.ly/37qy4hf

[23] I. Gutman and K. C. Das, "The first Zagreb index 30 years after", MATCH communications in mathematical and in computer chemistry, vol. 50, pp. 83-92, 2004. [On line]. Available: https://bit.ly/2B5AEwS

[24] I. Gutma and O. E. Polansky, Mathematical concepts in organic chemistry. Berlin: Springer, 1986, doi: 10.1007/978-3-642-70982-1

[25] I. Gutman and N. Trinajstić, "Graph theory and molecular orbitals. Total $\varphi$-electron energy of alternant hydrocarbons", Chemical physics letters, vol. 17, no. 4, pp. 535-538, Dec. 1972, doi: 10.1016/0009-2614(72)85099-1

[26] H. Hosoya, "On some counting polynomials in chemistry", Discrete applied mathematics, vol. 19, no. 1-3, pp. 239-257, Mar. 1988, doi: 10.1016/0166-218X(88)90017-0

[27] S. Hayat, M. A. Malik, and M. Imran, "Computing topological indices of honeycomb derived networks", Romanian journal of Information scien- 
ce and technology, vol. 18, no. 2, pp. 144-165, 2015. [On line]. Available: https://bit.ly/3flYtzh

[28] Y. Hu, X. Li,Y. Shi, T. Xu, and I. Gutman, "On molecular graphs with smallest and greatest zeroth-order general Randić index", МATCH сотmunications in mathematical and in computer chemistry, vol. 54, no. 2, pp. 425-434, 2005. [On line]. Available: https://bit.ly/3fsv8DD

[29] Y. Huang, B. Liu, and L. Gan, "Augmented Zagreb index of connected graphs", MATCH communications in mathematical and in computer chemistry, vol. 67, no. 2, pp. 483-494, 2012. [On line]. Available: https://bit.ly/2YyAENT

[30] Y. C. Kwun, M. Munir, W. Nazeer, S. Rafique, and S. M. Kang, "M-Polynomials and topological indices of V-Phenylenic Nanotubes and Nanotori", Scientific reports, vol. 7, no. 1, pp. Art ID. 8756, Aug. 2017, doi: 10.1038/s41598-017-08309-y.

[31] X. Li and I. Gutman, Mathematical aspects of Randic-type molecular structure descriptors, vol. 1. Kragujevac: University of Kragujevac, 2006.

[32] V. Lokesha and T. Deepika, "Symmetric division deg index of tricyclic and tetracyclic graphs", International journal of scientific \& engineering research, vol. 7 , no. 5, pp. 53-55, 2016. [On line]. Available: https://bit.ly/30G9ibm

[33] M. Munir, W. Nazeer, S. Rafique, and S. Kang, "M-Polynomial and related topological indices of nanostar dendrimers", Symmetry, vol. 8, no. 9, Art ID. 97, Sep. 2016, doi: 10.3390/sym8090097

[34] M. O'Keeffe, G. B. Adams, and O. F. Sankey, "Predicted new low energy forms of carbon", Physical review letters, vol. 68, no. 15, pp. 23252328, Apr. 1992, doi: 10.1103/PhysRevLett.68.2325

[35] K. Pattabiraman, "Inverse sum indeg index of graphs", AKCE international journal of graphs and combinatorics, vol. 15, no. 2, pp. 155-167, Jan. 2018, doi: 10.1016/j.akcej.2017.06.001

[36] M. Randić, "On history of the Randić index and emerging hostility toward chemical graph theory", MATCH communications in mathematical and in computer chemistry,vol. 59, no. 1. pp. 5-124, 2008. [On line]. Available: https://bit.ly/2XX0vjG 
[37] M. Randić, "On characterization of molecular branching", Journal of the American Chemical Society, vol. 97, no. 23, pp. 6609-6615, Nov.1975, doi: $10.1021 / \mathrm{ja} 00856 \mathrm{a} 001$

[38] G. Rücker and C. Rücker, "On topological indices, boiling points, and cycloalkanes", Journal of chemical information and computer sciences, vol. 39, no. 5, pp. 788-802, Jul. 1999, doi: 10.1021/ci9900175

[39] Y. Shi, "Note on two generalizations of the Randić index", Applied mathematics and computation, vol. 265, pp. 1019-1025, Aug. 2015, doi: 10.1016/j.amc.2015.06.019

[40] N. Trinajstić, S. Nikolić, A. Miličević, and I. Gutman, "O Zagrebaèkim indeksima", Kemija u industriji, vol. 59, no. 12, pp. 577-589, 2010. [On line]. Available: https://bit.ly/3d1gt0u

[41] D. Vukičević and A. Graovac, "Valence connectivities versus Randić, Zagreb, and modified Zagreb index: a linear algorithm to check discriminative properties of indices in acyclic molecular graphs", Croatica chemica acta, vol. 77, no. 3, pp. 501-508, 2004. [On line]. Available: https://bit.ly/2AnM2Ex

[42] D. Vukičević and B. Furtula, "Topological index based on the ratios of geometrical and arithmetical means of end-vertex degrees of edges", Journal of mathematical chemistry, vol. 46, pp. 1369-1376, Jan. 2009, doi: 10.1007/s10910-009-9520-x

[43] H. Wiener, "Structural Determination of Paraffin Boiling Points", Journal of the American Chemical Society, vol. 69, no. 1, pp. 17-20, Jan. 1947, doi: 10.1021/ja01193a005

[44] L. Zhong, "The harmonic index for graphs", Applied mathematics letters, vol. 25, no. 3, pp. 561-566, Mar. 2012, doi: 10.1016/j.aml.2011.09.059 